\title{
AC 2008-2814: ASSESSMENT OF A BLENDED PRODUCT LIFECYCLE MANAGEMENT COURSE UTILIZING ONLINE AND FACE-TO-FACE DELIVERY MECHANISMS
}

\section{Daniel Wittenborn, Purdue University}

Daniel Wittenborn is doctoral student in the College of Technology at Purdue University. He received a B.S. in Industrial Technology from Southeast Missouri State University and an M.S. in Computer Graphics Technology from Purdue University. While at Purdue, he has received the Outstanding Graduate Student Teaching Award and Schroff Award. He was also named a recipient of the Bilsland Dissertation Fellowship in 2007. Currently, his research interests include engineering education related to computer-aided design, manufacturing, and product lifecycle management programs. Upon completion of his Ph.D. in 2008, he will be employed with the Learning, Training and Development group at The Boeing Company.

\section{Michael Richey, The Boeing Company}

Michael Richey is a Boeing Associate Technical Fellow supporting the Learning Training and Development group. Michael has 30 years experience in tool design and metrology, analyzing commercial aircraft and has developed many advanced CAD/CAM and Product Lifecycle management standards and engineering educational programs. Michael is the industry representative for the FAA AMTAS Center of Excellent at the University of Washington and is the Chair of their A\&A Department's Aircraft Structures Composite and Manufacturing Certificate Programs. Michael received his B.S. in International Business from ESC Lille, Graduate School of Management. He is currently working on a Masters of Science in Program \& Project Management, focusing on Aerospace Engineering and Learning Science research. He often represents Boeing internationally and domestically as a presenter and has authored PLM integration patents primary relating to advanced aircraft construction, PLM-CAD-CAM metrology and Learning Science research.

\section{Craig Miller, Purdue University}

Craig L. Miller is a professor and a named University Faculty Scholar in the Department of Computer Graphics Technology of Purdue University at the West Lafayette, Indiana campus. He received his Bachelor of Science and Master of Education from Bowling Green State University and his doctorate from The Ohio State University. Dr. Miller's primary professional responsibility is undergraduate and graduate instruction in engineering and technical graphics specifically in CAD, PDM, and PLM concepts and software applications. He has been involved in industry/educational partnerships between the College of Technology at Purdue University and several different industries, primarily in instructional media design and training. In 2007 Dr. Miller received the College of Technology Engagement Award for his work with industry in PLM. Dr. Miller has presented over fifty papers at professional conferences in North America and Australia. He has been a co-author for the McGraw-Hill Graphics Series and has authored papers in journals on engineering and technical graphics curriculum development and implementation, CAD, PDM, PLM, instructional systems design and training, interactive multimedia, and visualization research. 


\title{
Assessment of a Blended Product Lifecycle Management Course Utilizing Online and Face-to-Face Delivery Mechanisms
}

\begin{abstract}
Employees in the fields of engineering and technology must frequently receive continuing education in order to remain competitive. One solution to this problem is to provide employees with continuing education from academic experts in a distance learning format; bridging the divide between academia and industry. This paper will introduce a study that investigated the effectiveness of a new blended learning course aimed at engineers actively engaged in industry by means of a mixed research methodology. Product Lifecycle Management (PLM) techniques and theories were taught, focusing on the area of solid part modeling and surface modeling using a high-end computer-aided design (CAD) software program. The 10-week course was delivered using a blended learning format in which both distance learning (through online lectures and demonstrations) and experiential learning (through hand's on computer labs) were incorporated. All of the students were engineers or technologists at The Boeing Company, located in the greater Seattle, Washington area. This study investigates the course through different methodologies (quantitative and qualitative), reporters (students and instructors), and information (course effectiveness, satisfaction, and transportability). A pre-test/post-test design was used to test the learning outcomes on PLM theoretical knowledge and CAD skills. Quantitative survey data were also collected from students and instructors in the form of Likertscale responses. In addition to these quantitative data, qualitative data were also collected. These data were obtained through short questionnaires throughout the course as well as follow-up interviews with students two months after the conclusion of the course. These interviews helped to enrich the quantitative data by providing explanations of students' experiences in the class in more detail and investigating how well the course content relates to their career. The two-month follow-up interviews with students also provided insight on the transportability of the course content into the employees' job tasks after completion of the course. The goal of this research is to determine if the teaching of PLM theories and high-end CAD skills can effectively be taught in a blended learning format.
\end{abstract}

\section{Introduction}

Historically, corporate educators do not incorporate Learning Science research methods into industry training programs and academia sometimes struggles to develop partnerships with industry in order to apply advancing technology, business processes, and global competencies needed to retool the $21^{\text {st }}$ century workforce. This research study is predicated on the following: supporting a strong academic-industry partnership model will provide the framework for the reexamination of instructional approaches in aeronautical and mechanical engineering, bridging the gap between theoretical and procedural knowledge.

\section{Design and Logic}

Recently there have been renewed initiatives aimed at developing rigorous standards for engineering education. ${ }^{1}$ Supporting this mindset, the nature of developmental research has been 
has been described as "The systematic study of designing, developing and evaluating instructional programs, processes and products that must meet the criteria of internal consistency and effectiveness". ${ }^{2}$ Central to the theme of advancing rigorous educational research, this research has leveraged the Type I developmental research framework which will be briefly described here.

\section{Research Methodology}

Richey $^{3}$ describes Type I developmental research as context-specific, usually involving field observations and/or case studies. Type I research primarily focuses on a product design, development, validation and evaluation of a specific tool, technique or program. This approach is holistic, comprehensive in nature and includes developers, designers, instructors, students and evaluators with a broad focus on the effectiveness of the program and is consistence with the applied research. Type I studies can be characterized by their reliance upon contextually specific projects and contextually specific conclusions. ${ }^{3}$ This approach includes improvements in the instructional program and the conditions which are conducive to efficient design, development, and/or evaluation of the instructional program. ${ }^{4,5,6,7}$ Additionally, some Type I developmental studies reflect traditional evaluations in which the actual development process is not formally addressed; rather, only the product or program evaluation is described. Regardless of the nature of the Type I study, the results are normally context and product specific, even though the implications for similar circumstances may be discussed. ${ }^{8}$

In the present study, the authors focus on Type I, field-based research, specifically focused on evaluating the research and practice of a Product Lifecycle Management certificate program. The framework is situation - specific, and integrates both professors through classroom lectures, and incumbent "practicing engineers" (students) through work experience and real-world case studies. This case-study approach to inquiry is typical in a Type I study when exploring contextually specific learning situations with multiple variables, process complexity, procedural and technological complexity. An example of this form of Type I developmental research is Richey and Dang's 9 article entitled, "The Boeing Company Advances Current Thinking About Continued Learning." This Type I study encompassed the design, development and evaluation of a composite program within an academic - corporate environment using practicing studentengineers.

The unique position within industry, allows the researchers in this study direct access to incumbent engineers and the opportunity to pragmatically validate theory-to-practice in a realworld environment, implementing current industrial engineering procedures, processes and methods. Within this applied framework, a holistic evaluation of the environment, learner, and technology used within a newly developed set of instructional materials was performed. The design and development of these materials will not be the covered here due to the condensed nature of this paper. Instead, this paper will focus on a detailed evaluation of a PLM certificate program, implemented in an academic - corporate environment. This developmental research will link learning theory to corporate practice, through virtual lectures - and an experiential "hands-on" lab environment. 


\section{Problem Formulation}

A study by Jensen and Raisor ${ }^{10}$ in 2000 examined a distance-based course using a high-end CAD package. This study found that it is possible to teach this type of course online and results showed that there were no significant differences between learning outcomes of students enrolled in the online version of the course versus students enrolled in the traditional version of the course. However, this investigation only provided quantitative results that lacked the ability to describe "how" or "why" different aspects of the course were or were not effective.

The present study sought to answer these questions of "how" and "why". The study was conducted between the Learning, Training and Development group at The Boeing Company and the Department of Computer Graphics Technology (CGT) at Purdue University. The primary focus of this program was to link the theoretical and practical application of PLM software to the engineering community, leveraging the combined intellect of the Purdue faculty and the industry subject matter experts. Instructional development, deployment and assessment activities were conducted simultaneously with a specific focus on understanding the artifacts that underlie the complex behavioral, social and technological phenomena within a collaborative learning environment. This includes actively pursuing the use of new technologies for educational research and developing solid assessments that link learning objectives to relevant real world applications. The assessment process of this study included qualitative and quantitative methods that measure knowledge transfer, application knowledge, behavior impact, and performance productivity validation.

The development research foci included:

- A documented process for the design, development and evaluation of the PLM Certificate program.

- Subjective learner and instructor assessments of the blended learning PLM course.

- Evaluation of student learning in the blended learning PLM course.

- Study of the implementation and use of technology within the design-development of the blended engineering PLM program.

\section{Design Methodology}

\section{Summary of Procedure}

The PLM course was a 10-week blended learning course. The first objective of this course, which dealt with the theory of PLM and its importance, was to educate engineers on how their decisions immediately affect the other engineers' activities. The second objective was for students to possess entry level knowledge and application of high end enterprise CAD software for engineering part and surface design in a PLM environment by the end of the course. The 10week course utilized a blended learning approach for the delivery of the instructional content. Each week consisted of a two-hour virtual class meeting and a two-hour traditional, instructor led lab session at a computer lab onsite at Boeing. 
In general, there are four specific reasons to evaluate training programs:

1. To justify the existence of the training program by showing how it contributes to the organizations objectives and goals

2. To decide whether to continue or discontinue training programs

3. To gain information on how to improve future versions of the training program.

4. To determine what the students learn from the training program ${ }^{11}$

This study sought to satisfy these reasons by determining performance on a pre-test and post-test related to course content, as well as student and instructor satisfaction of the delivery and format of the course. The Kirkpatrick Learning Evaluation Model, created by Donald Kirkpatrick in 1959, was used to guide the current study. Kirkpatrick's model has been widely used to evaluate workplace training programs. It was chosen for this study because of its ability to customize goals and outcomes before training begins. It also offers flexibility in encouraging trainers to borrow approaches, techniques and methods from others. ${ }^{12}$

\section{Kirkpatrick's Four Levels of Evaluation}

Within the corporate environment, course evaluation and learning return on investment is a strategic process that validates educational investment made by internal business units. In an effort to generate curriculums that can measurably impact the educational investment, several assessment models were considered for the current study. Participating faculty and industry members agreed to use the Kirkpatrick model due to its use of both ongoing (formative) and end product (application) evaluation techniques. Kirkpatrick's four levels of evaluation are:

- Level 1: Reaction - a measure of satisfaction (smile sheet)

- Level 2: Learning - a measure of learning (evaluation as a means of determining learner readiness for course)

- Level 3: Behavior - a measure of behavior change (sample follow up with learner and supervisor)

- Level 4: Results - a measure of results (follow up with business to determine if learning intervention impacted business metrics linked to course design) ${ }^{11}$

The goals of the Kirkpatrick evaluation surveys used in the current study were to provide a method to measure the effectiveness of the training program from a student and instructor perspective, and to identify opportunities for improvements. By adopting and modifying the Kirkpatrick model, data were gathered throughout the development process to ensure instructional goals are being met through student learning and validated through the business impacts of training.

The research method used ensured that the problems identified could be met through measurable objectives and provided a framework for evaluating the following questions: a) did the knowledge transfer, b) did the knowledge impact behaviors, and c) did the behaviors impact productivity and productivity of the product service offerings? This framework included instructor and student evaluations of the PLM course. This evidence based approach is a critical business component of most industrial training programs. 


\section{Instructor Led Online Lectures and Demonstrations}

As mentioned previously, one aspect of the PLM course was instructor led online lectures and demonstrations. Shea et $\mathrm{al}^{13}$ focused on two components of online teaching and learning, "teaching presence" and "community". According to their research, teaching presence is viewed as the core role of the online instructor and it is a promising mechanism for developing learning communities in online environments. Shea reveals that "a strong and active presence on the part of the instructor-one in which she or he actively guides and orchestrates the discourse-is related both to students' sense of connectedness and learning". For the two-hour virtual class meeting in the PLM course, all students met at the same time, but from different locations in a synchronous, interactive fashion. The first hour consisted of a theoretical lecture on a given aspect of PLM. The second hour consisted of a live demonstration of the CAD tool to help prepare students for lab exercises later in the week. Adobe Connect, formerly known as Macromedia Breeze, was used as the software tool to enable synchronous, web-based learning. The instructor used a webcam to allow for a live video feed to be broadcast; an effort to help provide a sense of presence within the virtual class. ${ }^{14}$ The instructor and students both used USB microphones during the course to facilitate two-way interactive discussions between the instructor and students, as well as between students themselves when appropriate. Modern education reformers emphasize the enormous benefits and attraction of interactivity and collaborative engagement. ${ }^{15}$ Online learning builds on these modern educational strategies, allowing for interactivity and collaboration through peer support and response. ${ }^{16}$ Furthermore, in a study by Ozan et al ${ }^{17}$, results indicated that students think they learn better when the overall utilization of distance education tools and technologies are more frequent. In particular, lectures with video and audio were found to be significant in determining the learning effectiveness in online settings.

\section{Supplemental Web-based Learning Modules}

Following the virtual session at the beginning of each week, students were instructed to use a self-learning, web-based training program created by the developer of the CAD program being taught. This software contained learning modules that relate to the CAD portion of the class and was used as supplementary learning for the students. Each module consisted of reading materials, embedded video-based examples of the CAD program operations and interactive exercises in which students can practice working in a simulated CAD environment, without actually having the CAD software itself. The training software enabled students to work at their own pace from home or any other location that has a computer and internet connection.

\section{Traditional Lab Sessions with Instructor}

The web-based training modules were also used to deliver exercises that had to be completed using the actual CAD program. These exercises were completed by the students during the twohour lab portion of the class each week. Due to the limited number of workstations in the computer labs available, the students were split into two divisions. Half of the students met in one lab and the other half in another lab at the same time. Each lab division was taught by a different lab instructor who was a subject matter expert at Boeing. Each lab instructor was 
available for the students during the lab to answer questions regarding the CAD software and the exercises assigned to them.

\section{Evaluation of the Course}

\section{Pilot Test}

For the current study, Kirkpatrick's Levels I, II, and parts of Level III evaluation were implemented. Due to its complexity and cost, Level IV was not a part of this study. Multiple methods of Level I evaluation were developed for this study. To begin, a pilot test, considered a type of formative evaluation, was performed with individuals to help determine if the training program was effective. Participants in the pilot test were employees from the Learning, Training, and Development program of The Boeing Company. A mix of people with and without previous knowledge of the course content participated. This accounted for both face validity and content validity of the materials being presented. Most participants had a similar educational background in the area of engineering as the expected target population. Managers of the pilot test participants confirmed this. The pilot test replicated all aspects of the lecture and lab planned for week one of the full course. Data were collected by means of two separate online surveys; one pertaining to the online lecture portion of the training and the other to the traditional lab portion of the training. Both surveys addressed the delivery of the blended-learning course, specifically the format and technologies used. The goal was to assess whether or not the course could be effectively taught using the established delivery mechanisms. The lecture survey consisted of six Likert-style responses and five open-ended questions. Participants were asked to supply their opinions on areas such as: audio and video quality, ability to follow along, performance of the software and technology used and participant interaction. Participants were also asked to give comments on any additional suggestions for improvement of the online portion of the course. The lab survey consisted of five Likert-style responses and two open-ended questions. Topics on this survey included previous experience with software being taught, design of the lab exercises, quality of the instructor, and suggestions for improvement. Conclusions from the lecture survey were that an upgraded microphone, higher bandwidth, and more interaction with students were high priorities for improvement. The lab surveys indicated that increasing the amount of time spent by the instructor demonstrating the software and exercises could be helpful.

\section{Participants}

Participants for this study included engineers and technologists who were employed at The Boeing Company in the greater Seattle, Washington area. These employees were enrolled in the first of three courses offered as part of the Purdue University Product Lifecycle Management Certificate Program. This first course was offered in the summer of 2007 and was entitled, "Introduction to 3D CAD Design in PLM Environments". A short demographic survey was given to the students prior to beginning the course. Variables such as age, gender, years with current company, previous experience in a distance learning course, experience with related course content, and attitude towards distance learning were examined by instructors to determine the attitudes and perceived abilities of the students coming into the course. This survey was both created and delivered in a web-based format using software called Survey Builder. Participation in all surveys and interviews throughout this study were deemed voluntary and anonymous to 
everyone other than the researcher. After the data were collected, student names were stripped away and ID codes were used throughout the study. There were 23 students who enrolled in the course but due to attrition only 18 students completed the course and participated in the research study. Conversations with students who dropped out of the program revealed that four of them did so because of time issues with work or family and the fifth decided that the distance format and difficulty of the content were not appropriate for him. Age ranges were fairly balanced across the students; however, the number of males in the course far outweighed the number of females. Furthermore, although students seemed to have a high level of comfort with distance learning, their knowledge of the subject matter hedged towards the moderate and poor understanding levels. The expanded results from the pre-course demographic survey are shown in Table 1 below.

Table 1. Frequency counts from Demographic Survey results.

\begin{tabular}{|c|c|c|c|c|c|c|}
\hline \multirow{2}{*}{ Age } & $18-25$ & $26-35$ & $36-45$ & $46-55$ & $56+$ & $N / A$ \\
\hline & 5 & 4 & 4 & 3 & 1 & 1 \\
\hline \multirow[t]{2}{*}{ Gender } & Male & Female & & & & \\
\hline & 15 & 3 & & & & \\
\hline \multirow[t]{2}{*}{ Prev Dist Ed Exp } & Yes & No & & & & \\
\hline & 6 & 12 & & & & \\
\hline \multirow[t]{2}{*}{$\begin{array}{l}\text { Expectations of } \\
\text { Course }\end{array}$} & Very Difficult & Difficult & $\begin{array}{r}\text { Somewhat } \\
\text { Difficult }\end{array}$ & Easy & Very Easy & $N / A$ \\
\hline & 2 & 3 & 6 & 3 & 1 & 3 \\
\hline \multirow[t]{2}{*}{$\begin{array}{l}\text { Highest Level of } \\
\text { Ed }\end{array}$} & High School & Associate's & Bachelor's & Master's & Ph. D. & $N / A$ \\
\hline & 1 & 5 & 8 & 1 & 0 & 3 \\
\hline \multirow[t]{2}{*}{$\begin{array}{l}\text { Level of Comfort } \\
\text { in Dist Ed Class }\end{array}$} & $\begin{array}{r}\text { Very } \\
\text { Comfortable } \\
\end{array}$ & Comfortable & $\begin{array}{r}\text { Somewhat } \\
\text { Comfortable }\end{array}$ & Uncomfortable & $\begin{array}{r}\text { Very } \\
\text { Uncomfortable }\end{array}$ & $N / A$ \\
\hline & 8 & 5 & 3 & 0 & 0 & 2 \\
\hline \multirow[t]{2}{*}{ CAD Proficiency } & $\begin{array}{r}\text { Very } \\
\text { Proficient } \\
\end{array}$ & Proficient & $\begin{array}{r}\text { Somewhat } \\
\text { Proficient }\end{array}$ & Nonproficient & $\begin{array}{r}\text { Very } \\
\text { Nonproficient } \\
\end{array}$ & $N / A$ \\
\hline & 2 & 3 & 2 & 5 & 4 & 2 \\
\hline \multirow[t]{2}{*}{$\begin{array}{l}\text { Understanding of } \\
\text { PLM }\end{array}$} & $\begin{array}{r}\text { Very good } \\
\text { understanding }\end{array}$ & $\begin{array}{r}\text { Good } \\
\text { understanding }\end{array}$ & $\begin{array}{r}\text { Moderate } \\
\text { Understanding } \\
\end{array}$ & $\begin{array}{r}\text { Poor } \\
\text { understanding }\end{array}$ & $\begin{array}{r}\text { Very poor } \\
\text { understanding }\end{array}$ & $N / A$ \\
\hline & 1 & 4 & 5 & 3 & 3 & 2 \\
\hline
\end{tabular}

\section{Weekly Questionnaires}

Another method for collecting Level I data was with a brief weekly questionnaire to address student satisfaction of the course content and two additional bi-weekly questionnaires pertaining to the instructors/delivery and the technology being used. All participating students were asked to complete these weekly and bi-weekly surveys that were delivered online. The weekly course 
content survey covered both the lecture and lab potion of the class together since the content was similar for each. There were separate instructor and technology surveys for the lecture and lab portions since each will be different in these regards. All surveys were brief, four to six Likertstyle questions, with one open-ended response at the end for additional comments. The goal was that each survey will be able to be completed in less than five minutes. This was important to keep participants from being overwhelmed. ${ }^{18}$

In most cases, the students expressed that the lecture content was compelling and applicable their current job, both directly and indirectly. They thought that the changes underway at Boeing were exposed in a different light by having been discussed in the context of this course. They were able to see how the use of CAD fit within the larger PLM environment. In general, the lecture content was rated as above-average or higher in nearly all cases. However, the students did express some concerns regarding the lab content and infrastructure. One example of this appears in week four of the data shown in Figure 1 and Figure 2 below. The content from this week rated much lower on these two measures than most other weeks. This content covered material that is not used by engineers at Boeing, thus it was not as related to their interests and was difficult for them to understand. Week nine also scored lower on average; however, this week was a review session for the final and was treated differently than the rest of the weeks.

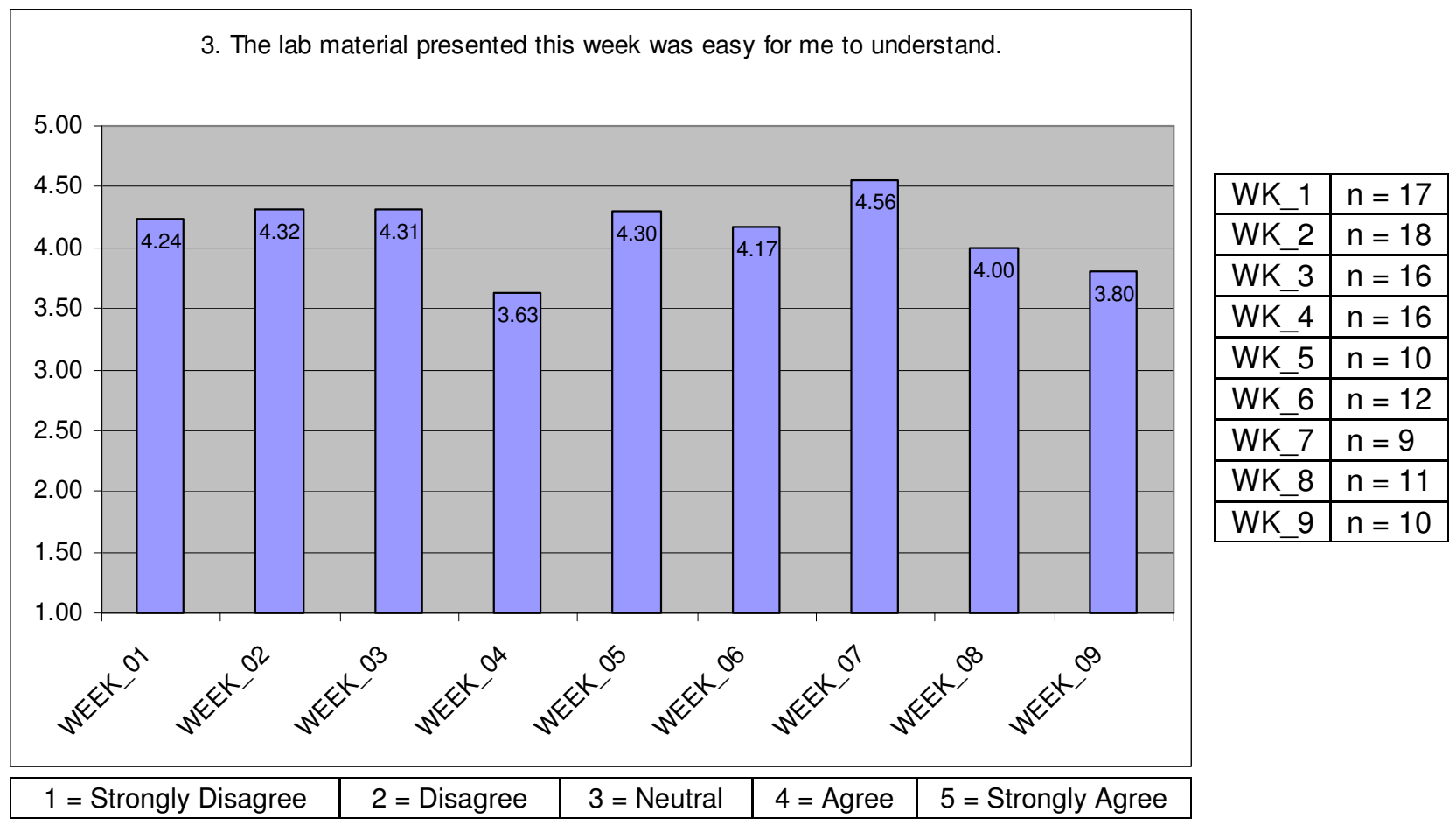

Figure 1. Survey results from Question 3 of the weekly student questionnaire on course content. 


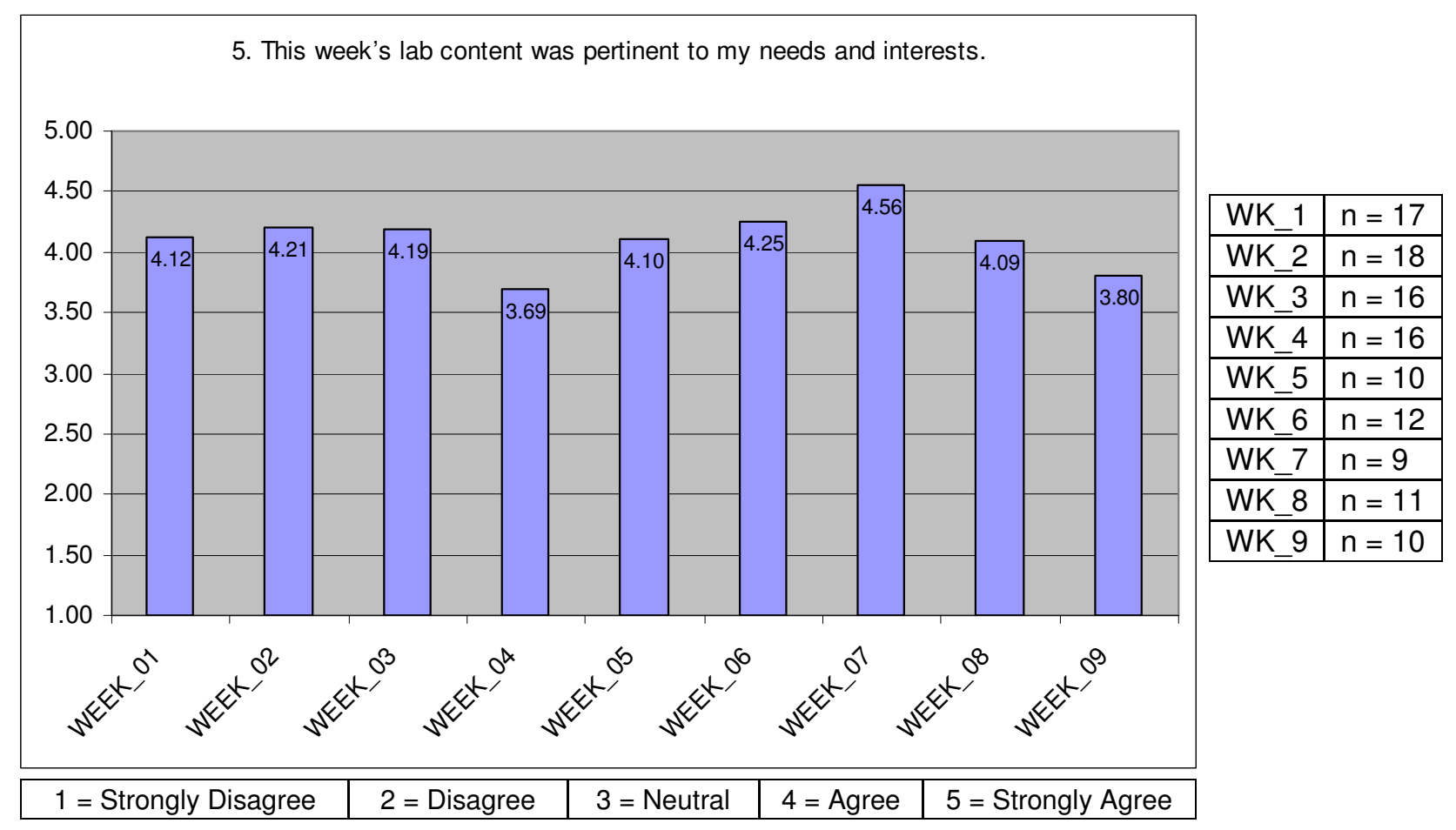

Figure 2. Survey results from Question 5 of the weekly student questionnaire on course content.

\section{Pre-test and Post-test assessments}

As mentioned previously, one objective of this course was to educate the students on the theory of PLM and its importance. The second objective was to train the students so they would possess a beginning knowledge of how to utilize 3D CAD solid and surface design, allowing for the integration PLM. In order to fulfill these two objectives and to perform a summative evaluation, the students enrolled in the course were asked to complete a pre-test analysis prior to the first virtual class meeting. This test consisted of two distinct parts, the first of which ascertained their existing knowledge relating to the theory of PLM and the second on their existing knowledge of the CAD program. The PLM portion of the assessment was paper-based with multiple styles of questions that included multiple choice, fill in the blank, matching and short answer. In order to assess CAD proficiency a performance-based test was used. Students were given a drawing of a part, including dimensions and additional design requirements that had to be incorporated to satisfy the design intent of the part. Students were then instructed to use the CAD software to design the part as completely as they could per the instructions provided. Students were given one hour to complete each component of the assessment, thus, two hours total. Prior to grading these assessments, rubrics were created for both portions in order to remove subjectivity form the grading and increase reliability. Both rubrics were reviewed by subject matter content experts and an instructional design expert specializing in evaluation. These reviews and subsequent revisions provided a strong form of both content and face validity to these assessments. The results of the pre-test and post-test are shown in Figure 3 below. It should be noted that these assessments were purposefully made very difficult in order to eliminate the chance of a ceiling effect in this study. Thus, post-test scores were lower than what one might typically expect. 


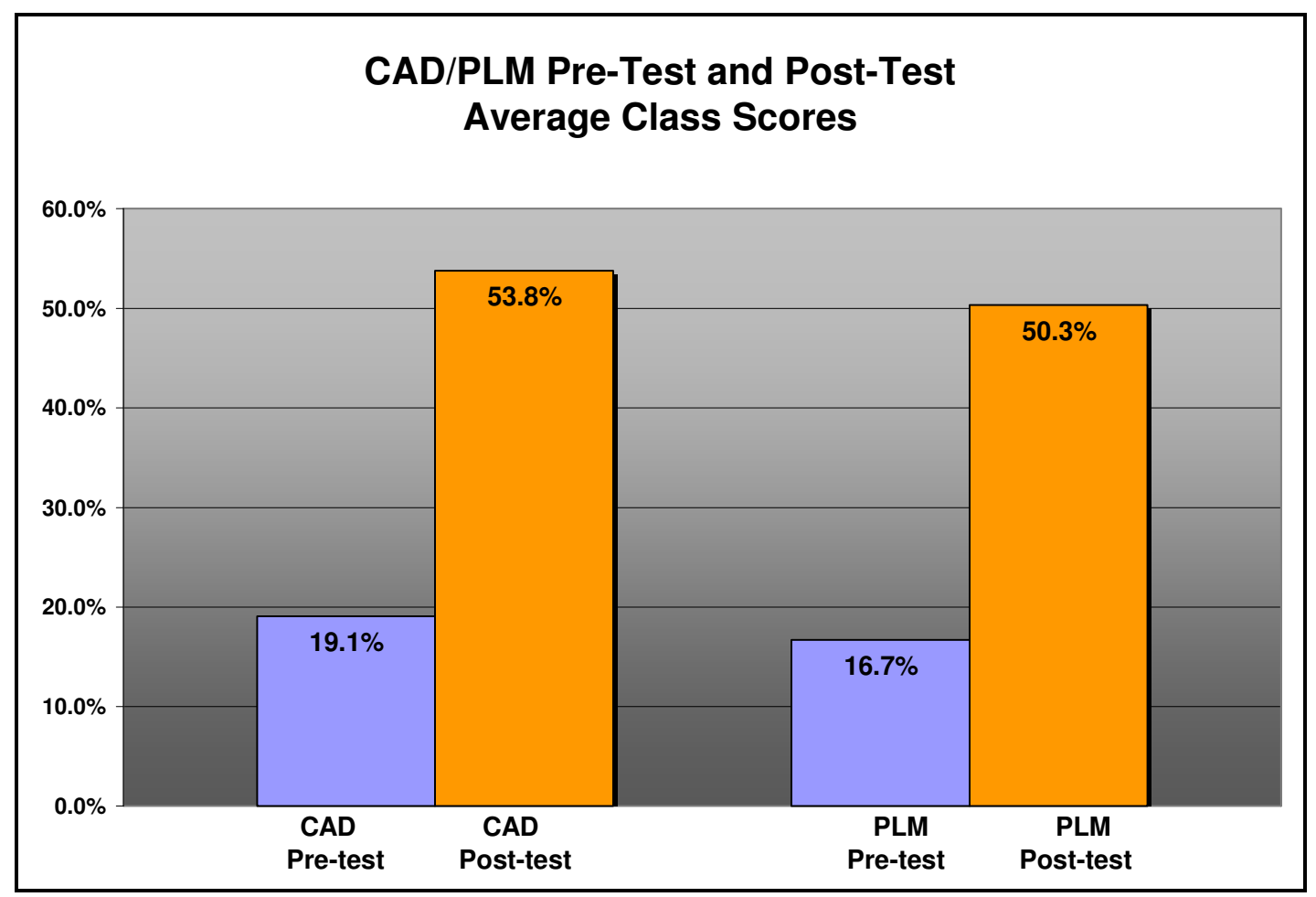

Figure 3. Average class scores on the CAD and PLM pre-test and post-test assessments.

A paired t-test was done on the scores using SPSS statistical software. In this case, the scores for both the CAD and PLM assessments increased significantly from the pre-test to the post-test, $\mathrm{t}(15)=6.2, \mathrm{p}=.000$ and $\mathrm{t}(15)=10.1, \mathrm{p}=.000$ respectively. This is shown in Table 2 below. Another interesting observation from these results is that the performance-based CAD portion and the written PLM portion both showed a nearly an identical gain, even though the subject matter and format of both portions of the assessment were different.

Table 2. Results from paired t-test comparing pre-test scores to post-test scores on the CAD and PLM assessments.

Paired Samples Test

\begin{tabular}{|c|c|c|c|c|c|c|c|c|c|}
\hline & \multicolumn{5}{|c|}{ Paired Differences } & \multirow[b]{3}{*}{$\mathrm{t}$} & \multirow[b]{3}{*}{$\mathrm{df}$} & \multirow[b]{3}{*}{ Sig. (2-tailed) } \\
\hline & & \multirow[b]{2}{*}{ Mean } & \multirow[b]{2}{*}{ Std. Deviation } & \multirow{2}{*}{$\begin{array}{l}\text { Std. Error } \\
\text { Mean }\end{array}$} & \multicolumn{2}{|c|}{$\begin{array}{l}95 \% \text { Confidence } \\
\text { Interval of the } \\
\text { Difference }\end{array}$} & & & \\
\hline & & & & & Lower & Upper & & & \\
\hline Pair & CADpre - CADpost & -33.31250 & 21.35640 & 5.33910 & -44.69252 & -21.93248 & -6.239 & 15 & .000 \\
\hline Pair 2 & PLMpre - PLMpost & -33.52500 & 13.25401 & 3.31350 & -40.58756 & -26.46244 & -10.118 & 15 & .000 \\
\hline
\end{tabular}

\section{End of Course Student Surveys}

With respect to the end of the course surveys, when asked to respond to the statement, "Overall, I really enjoyed the lectures" in a post-course survey, the mean response was $4.2(\mathrm{n}=11,5$ point scale, 1 = Strongly Disagree, $2=$ Disagree, $3=$ Neutral, $4=$ Agree, $5=$ Strongly Agree) . Additionally, when asked to respond the statement "I would recommend the use of Adobe Connect in future learning courses" in the same post-course survey with the same scale, the mean response was 4.5. Qualitative data supporting these results include post-course student comments 
such as: "This is my third online course, and by far the best regarding the online technology. The Adobe Connect software really brings the classroom to you online, allowing great participation between the student, professor and other classmates." and "I have a better opinion of online virtual lectures than I did before. It worked out better than expected..."

While the use of online learning technologies was rated highly, the students were not as satisfied with the technology used to deliver the lab exercises. Students stated that the web-based training software used to deliver the lab exercises was not particularly user friendly and that some of the content was too generic. Students emphasized that they would like to see lab exercises that were more customized and closely aligned with Boeing practices. Students also expressed that they would like to be able to continue working on laboratory exercises from home because they felt that in some cases, two hours was not enough time to complete the laboratory exercises in lab.

\section{End of Course Instructor Surveys}

At the conclusion of the course, the online instructor and the lab instructors were all surveyed to gather another perspective on the perceived successfulness of the class. Each of the lab instructors believed that the lab content used to teach the course was not completely appropriate in terms of subject matter. The main reasons stated for this were that the subject matter was too generic and broad, rather than focusing on the objectives of the course. It was also stated that much of the content was far too advanced for an introductory CAD course. The lab instructors also reiterated that students had a hard time finishing the lab exercises within the two-hour time block allotted for each week's lab. Suggestions were made to increase the lab to three hours each week or find a way to give students access to the CAD software from home.

The online instructor responded to the survey by stating that all of the lecture content used to teach this course seemed to be appropriate in terms of subject matter. One particular component of the online lectures that he felt needed attention was improving the student interaction, with both the instructor and other students. The instructor suggested that by posting discussion questions online pertaining to the assigned reading, the students would generate ideas prior coming to class and a livelier discussion might take place online. The instructor also emphasized the need to create a stronger relationship between the assigned reading materials and the content presented during the lecture. Lastly, the online instructor suggested that increasing the number of software demos during the online portion of the class might be beneficial to the students, better preparing them for the lab exercises assigned to them later in the week.

\section{Post Course Student Interviews}

For the purpose of Level III evaluation in the present study, five students were interviewed two months after the conclusion of Course 1. These interviews attempted to gain a deeper understanding of students' satisfaction with the course and enrich the data collected by the questionnaires. They also attempt to determine the amount of knowledge that has been transferred from the training program to their performance in the workplace. By approaching the evaluation from three different directions, student surveys, student interviews, and instructor surveys, triangulation of the data was achieved and the credibility of the qualitative data was enhanced. ${ }^{19}$ The five students interviewed were randomly selected from a pool of students who 
answered yes to a question on the demographic survey regarding their willingness to participate in a post course interview. The interviews were semi-structured in nature and lasted about 17 minutes each on average. The interviews were conducted online using a private meeting in Adobe Connect and the audio was recorded for transcription at a later time. This qualitative data was then transcribed and coded using NVivo statistical software to examine emerging themes in employees' responses.

There were four main themes that emerged from the student interviews. The first was a negative attitude towards the web-based training software used to deliver the lab exercises. It was described as being difficult to use and distracted from learning the CAD software, rather than enabling it. The second theme that emerged was a need to add better organization to the class, especially with half the class being delivered online. An idea that was suggested was to use an electronic learning management system (ELMS) in the future. A third theme was the desire to be able to work on the labs from home. Finally, one last major theme that emerged from the student interviews was an overall high degree of satisfaction with the course in general. All five students stated that they were glad they enrolled in the course and that they felt they learned a great deal that could be applied to their career either currently or in the near future. One student commented, "I definitely liked learning about the PLM theories in the course, rather than just learning how to use CAD software. You can learn how to use the software, but understanding why you are using it and how it can be implemented correctly is equally important." Additionally, when asked if they would recommend this course to others, all the students responded that they either already had, or plan to do so.

\section{Recommendations}

As is normally the case for Type I developmental research studies, the results from this investigation have yielded recommendations that are of specific interest to the course being reviewed. However, many of these recommendations can also be generalized to other distance or blended learning courses; especially those focused on teaching technical content and applications. The review of literature, experiences of the authors in conducting the study, and the statistical results of the study serve as a basis for the following recommendations:

- Much of the lab content was far too advanced for this introductory level course. The labs should focus on the basics of CAD part design.

- Use web-based CAD training for pre-lab reading and as supplemental reference material, rather than relying on it to deliver lab exercises.

- Developing a series of problem-based learning (PBL), aircraft-related, lab exercises that build off each other over the span of the course. At the end of the course the parts created from these exercises should be able to be assembled to create a complete assembly.

- The lab content for week four in particular needs to be removed from the course.

- Improve the communication between instructors and students and organize lecture and lab assignments by implementing an electronic learning management system (ELMS) such as Blackboard.

- Post discussion questions and readings online prior to class. Require students to post responses and reply to other students' responses within the discussion forum on a weekly basis. 
- Increase utilization of the audio capabilities by the students during the online lectures.

- Create a stronger relationship between the assigned readings and the lecture content.

- Add more knowledge assessment (formal or informal quizzes) throughout the course, rather than just relying on a final exam to assess learning.

- The largest hurdle for the delivery of a course that utilizes high end software is the IT overhead. In the future any attempt at delivering a PLM centered curriculum even in a traditional setting will require dedicated IT support. When distance delivery is factored into the equation and trying to replicate an industry setting the IT overhead only increases. Do not attempt a PLM centered curriculum without the support of a fulltime IT technician who will install and administer this type of IT environment.

\section{Conclusion}

This paper has summarized the findings of this Type I developmental research study as related to the goals of the project. Based upon the quantitative and qualitative analysis performed, the newly developed blended-learning course educating incumbent engineers on PLM theories and high-end CAD skills was found to be an overall success by both students and instructors. Recommendations have been made to improve future offerings of both this course and other related programs. Many of these recommendations have already been incorporated into the second course of the three-course Purdue University PLM Certificate Program. The second course focuses on relational design methodologies and builds upon the concepts taught in Course 1 , as discussed in this paper. The results detailing the effects of implementing the recommendations mentioned above within Course 2 will be presented in future papers.

\section{Bibliography}

1. Shavelson, R., \& Towne, L. Scientific Research in Education, Washington D.C.: National Academies Press, 2002.

2. Seels, B. B., \& Richey, R. C. (1994). Instructional technology: The definition and domains of the field. Washington, DC: Association for Educational Communications and Technology.

3. Richey, R. C. (1997). Research on Instructional Development. Educational Technology, Research and Development, 45(3), 91-100.

4. Alessi, S.M. (1988). Learning interactive videodisc development: A case study. Journal of Instructional Development, 11(2), 2-7.

5. Link, N., \& Cherow-O'Leary, R. (1990). Research and development of print materials at the Children's Television Workshop. Educational Technology Research \& Development, 38(4), 34-44.

6. Dick, W. (1991). The Singapore project: A case study in instructional design. Performance Improvement Quarterly, 4(1), 14-22.

7. Jonassen, D.H. (1988). Using needs assessment data to design a graduate instructional development program. Journal of Instructional Development, 11 (2), 14-23. 
8. Richey, R. C., Klein, J. D., \& Nelson, W. A. (2004). Developmental Research: Studies of Instructional Design and Development. In D. H. Jonassen (Ed.), Handbook of Research on Educational Communications and Technology (2nd ed., pp. 1099-1130). Mahwah, NJ: Lawrence Erlbaum Associates Publishers.

9. Richey, M., Dang, V., Lin, K., Bransford, J.D., Vye, N., \& O’Mahoney, T. K. (2007). “The Boeing Company Advances Current Thinking about Continued Learning." Paper presented at the American Educational Research Association Annual Meeting, Chicago, IL, April 9-13.

10. Jensen, C. G., \& Raisor, E. M. (2000). Integrating engineering theory and practicum within interactive asynchronous courses. Paper presented at the ASME International Mechanical Engineering Congress and Exposition, Orlando, FL, November 5-10.

11. Kirkpatrick, D. (1998). Evaluating Training Programs (2nd ed.). San Francisco, CA: Berrett-Koehler.

12. Galloway, D. L. (2005). Evaluating distance delivery and E-learning: is Kirkpatrick's model relevant? Performance Improvement, 44(4), 21-27.

13. Shea, Peter, Chun Sau Li, Alexandra Pickett. (2006). A study of teaching presence and student sense of learning community in fully online and web-enhanced college courses. Internet and Higher Education (9), 175-190.

14. Simonson, M., Smaldino, S., Albright, M., \& Zvacek, S. (2006). Teaching and learning at a distance: Foundations of distance education (3rd ed.). Upper Saddle River, NJ: Pearson Education.

15. Bransford, J., Brown, A., Cocking, R. How People Learn: Brain, Mind, Experience and School. Committee on Developments in the Science of Learning with additional material from the Committee on Learning Research and Educational Practice, National Research Council 2000.

16. Fisher, F., Hadim, H. \& Esche, S. (2007). Feasibility of a fully online undergraduate Mechanical Engineering degree for non-traditional learners. Proceedings of the 2007 ASEE Annual Conference and Exposition, June 24-27, 2007, Honolulu, Hawaii.

17. Ozan, E., Tabrizi, M., Wuensch, K., Aziz, S., \& Kishore, M. (2007). Learning effectiveness as a function of technologies employed in online learning systems. Proceedings of the 2007 ASEE Annual Conference and Exposition, June 24-27, 2007, Honolulu, Hawaii.

18. Robinson, D. G., \& Robinson, J. C. (1989). Training for Impact (1st ed.). San Francisco, CA: Jossey-Bass.

19. Patton, M. Q. (2002). Qualitative research and evaluation methods (3rd ed.). Thousand Oaks, CA: Sage. 